Moral-Rodríguez AI, Leyva-Ramos R, Ania CO, Ocampo-Pérez R, Isaacs-Páez ED, Carrales-Alvarado DH, Parra JB, Tailoring the textural properties of an activatedcarbon for enhancing its adsorption capacity towards diclofenac from aqueous solution, Environ.

Sci. Poll. Res. (2019) 1-12.

$10.1007 / \mathrm{s} 11356-018-3991-\mathrm{x}$

hal-02318749v1

\title{
TAILORING THE TEXTURAL PROPERTIES OF AN ACTIVATED CARBON FOR ENHANCING ITS ADSORPTION CAPACITY TOWARDS DICLOFENAC FROM AQUEOUS SOLUTION
}

Adriana I. Moral-Rodríguez ${ }^{1}$, Roberto Leyva-Ramos ${ }^{1}$, Conchi O. Ania ${ }^{2}$, Raul Ocampo-Pérez ${ }^{1}$, Elizabeth D. Isaacs-Páez ${ }^{1}$, Damarys H. Carrales-Alvarado ${ }^{1}$, Jose B. Parra ${ }^{3}$

${ }^{1}$ Centro de Investigación y Estudios de Posgrado, Facultad de Ciencias Químicas, UASLP, Av. Dr. Manuel Nava No. 6, San Luis Potosí, SLP 78210, México

*E-mail: rlr@uaslp.mx

${ }^{2}$ POR2E Group, CEMHTI (UPR 3079) CNRS, Univ. Orléans, Orléans, France

${ }^{3}$ Instituto Nacional del Carbón (INCAR, CSIC), Oviedo, España 


\begin{abstract}
A series of activated carbons (ACs) were prepared by modifying a commercial AC by physical activation using $\mathrm{CO}_{2}$ during different activation times. The ACs were designated as F, F12, F24 and F40 corresponding to the activation times of $0,12,24$ and 40 hours, respectively. The surface area, total pore volume, micropore volume and mean micropore width were determined for all the ACs. The textural properties of the modified ACs increased substantially with the activation time, and the capacity of the ACs for adsorbing diclofenac (DCF) was almost linearly dependent upon the surface area of the ACS. The maximum adsorption capacities of F, F12, F24 and F40 carbons towards diclofenac (DCF) from aqueous solution were 271, 522, 821 and 1033 $\mathrm{mg} / \mathrm{g}$, respectively. Hence, the adsorption capacities of ACs were considerably enhanced with the activation time, and F12, F24 and F40 carbons presented the highest adsorption capacities towards DCF reported in the technical literature. The F40 adsorption capacity was at least twice those of other carbon materials. The adsorption capacities decreased by raising the $\mathrm{pH}$ from 7 to 11 due to electrostatic repulsion between the ACs surface and anionic DCF in solution. The removal of DCF from a wastewater treatment plant (WWTP) effluent was effectively carried out by adsorption on F40. Hence, the capacity of ACs for adsorbing DCF can be optimized by tailoring the porous structure of ACs.
\end{abstract}

Keywords: Activated carbon; Adsorption; $\mathrm{CO}_{2}$ activation; Diclofenac; Microporosity; Tailoring porosity 


\section{INTRODUCTION}

Potential environmental and health problem due to water contamination caused by the presence of emerging pollutants is attracting attention to the society. Due to their worldwide consumption, pharmaceuticals and their metabolites represent an overwhelming portion of trace emerging contaminants detected in surface and drinking water, groundwater, and wastewaters (Houeto et al. 2012). Most commonly found pharmaceutical pollutants in effluents from wastewater treatment plants (WWTP) are antibiotics, antacids, antidepressants, analgesics, antipyretics, steroids, anti-inflammatory, $\beta$-blockers, tranquilizers and stimulants (Ternes 1998; Daughton and Ternes 1999; Rivera-Utrilla et al. 2009).

Nowadays, the non-steroidal anti-inflammatory drugs (NSAIDs) are extensively prescribed to cure many diseases and are the most widely used therapeutic group worldwide, which has led to its presence in different groundwater or surface water sources. Diclofenac (DCF) is an NSAID drug and is employed to decrease swelling and alleviate pain in pathologies such as rheumatoid arthritis. DCF has the highest critical toxicity within the NSAIDs, with a half maximal effective concentration $\left(\mathrm{EC}_{50}\right.$ ) less than $100 \mathrm{mg} / \mathrm{L}$ (Cleuvers 2003), and can be found in drinking water, groundwater, WWTP effluents and surface water supplies in several countries at concentration levels varying from $\mathrm{ng} / \mathrm{L}$ to $\mu \mathrm{g} / \mathrm{L}$ (Houeto et al. 2012).

The concentrations of pharmaceuticals in water resources seldom exceed the curative doses, but they are steadily released to the environment; so the concentrations remain almost constant, posing a critical hazzard to human health and environment (Richards et al. 2004). Most of them are hardly biodegradable and can be poorly eliminated and biodegraded by traditional biological treatment. Therefore, elimination of pharmaceuticals in WWTPs is a crucial topic of interest (Ternes et al. 2002; Clara et al. 2005; Watkinson et al. 2007; Kasprzyk-Hordern et al. 2009; Rúa-Gómez and Püttmann 2012), and there is a pressing need for improving current 
treatment technologies. The efficiency of activated carbon adsorption technology as an end-ofpipe technology to upgrade existing WWTP to remove the emerging micropollutants has long been investigated (Carvalho et al. 2012, 2013).

The modification of activated carbons (ACs) for improving their capacities for adsorbing DCF has been studied in few works. For instance, Álvarez Torrellas et al. (2015) investigated the adsorption of diclofenac on chemical-activated carbon synthesized from peach stones. This AC was chemically modified with an $\mathrm{HNO}_{3}$ solution to increase the acidic sites and was thermally modified to decrease the acidic groups. The pristine AC and the two modified ACs showed no adsorption capacity towards DCF for concentrations less than $20 \mathrm{mg} / \mathrm{L}$, attributing this behavior to weak DCF-adsorbent interactions. In contrast, for concentrations above $20 \mathrm{mg} / \mathrm{L}$, the uptake of DCF was continually increased by raising the concentration, and the capacity of pristine AC reached $200 \mathrm{mg} / \mathrm{g}$ for a concentration of DCF at equilibrium of $70 \mathrm{mg} / \mathrm{L}$. Furthermore, the thermal modification of AC did not substantially influence the adsorption capacity, whereas the chemical modification reduced the adsorption capacity. Saucier et al. (2015) analyzed the pH dependence of the adsorption equilibrium and kinetics of DCF from aqueous solution on an AC produced by microwave-assisted chemical activation of coconut shell. The findings showed that the maximum uptake of DCF adsorbed was $63.47 \mathrm{mg} / \mathrm{g}$ at an optimal $\mathrm{pH}=7$. Álvarez et al. (2015) analyzed the adsorption of DCF on chemically modified carbon xerogels, attaining uptakes of 182.5 and $80 \mathrm{mg} / \mathrm{g}$ for the materials modified with urea and sulfuric acid, respectively. Lastly, the competitive adsorption of diclofenac in the presence of salicylic acid, acetylsalicylic acid and atenolol on three commercial ACs was examined by Rakić et al. (2015), with adsorption capacities ranging from 13.8 to $31 \mathrm{mg} / \mathrm{g}$ for all four pollutants. 
In previous studies, it has been reported that the adsorption capacities of the ACs towards DCF varied from 13.8 to $347 \mathrm{mg} / \mathrm{g}$; this is an essential issue for screening the adequate carbon adsorbent to be integrated into current water treatment technologies for removing DCF. The relation between the adsorption capacity of AC towards DCF and the surface chemistry of AC has been addressed; nevertheless, the role of the porous structure (surface area, pore diameter and pore volume) on the adsorption capacity has not been investigated completely. Consequently, the purpose of this work was to find out the relationship between the adsorption capacity of ACs towards DCF and their textural properties and to substantiate the optimal characteristics of an AC to maximize the capacity for adsorbing DCF. This work was aimed at preparing a series of nanoporous carbons by modifying a commercial AC by physical activation with $\mathrm{CO}_{2}$ and varying the activation time, to develop further the porous structure and improve the adsorption capacity towards DCF from water solution. Additionally, the porous structure of ACs considerably affected the adsorption capacity, and the mechanism of DCF adsorption on AC was elucidated by conducting adsorption experiments at different $\mathrm{pH}$.

\section{EXPERIMENTAL METHODS}

\subsection{Materials}

A commercial microporous carbon (sample F) obtained by steam activation of coconut shell (CPL, Carbon Link) was selected for this study. The particle size of carbon F ranged from 0.40 to $0.75 \mathrm{~mm}$. Three nanoporous carbons having increasing burn-off degree were prepared by activating the carbon $\mathrm{F}$ under a $\mathrm{CO}_{2}$ atmosphere $\left(5^{\circ} \mathrm{C} / \mathrm{min}\right.$ up to $850{ }^{\circ} \mathrm{C}$ in $100 \mathrm{~mL} / \mathrm{min} \mathrm{N}_{2}$, afterward change to $\mathrm{CO}_{2}, 10 \mathrm{~mL} / \mathrm{min}$ ) (Gomis-Berenguer et al. 2016) during times of 12, 24 and $40 \mathrm{~h}$. The carbon samples were designated as F12, F24 and F40, respectively. 


\subsection{Chemical and textural properties}

The elemental composition of the ACs was quantified using elemental analyzers. The carbon, hydrogen and nitrogen were determined by a LECO CHNS-932 (ASTM D-5373), sulfur was quantified by a LECO S-144DR (ASTM D-4239) analyzer, and oxygen was evaluated with a LECO VTF-900 CHNS-932 microanalyzer. All the analysis have been done at least in triplicates with a standard deviation below $2 \%$. Besides, the $\mathrm{pH}$ at the point of zero charge $\left(\mathrm{pH}_{\mathrm{PZC}}\right)$ was determined using a modification of the mass-titration method detailed elsewhere (Ania et al. 2007).

The porous structure of the samples was analyzed using the $\mathrm{N}_{2}$ adsorption-desorption isotherms at $77 \mathrm{~K}$. The measurements were performed in a high-resolution physisorption analyzer, Micromeritics, ASAP 2020, equipped with three pressure transducers and a molecular pump, allowing to improve the sensitiveness at low pressures. Strict conditions were programmed to ensure $\mathrm{N}_{2}$ adsorption equilibrium so that the determination of each isotherm lasted on average between 90 and $120 \mathrm{~h}$. Prior to the measurement, the outgassing of the carbon samples was carried out at $120^{\circ} \mathrm{C}$ overnight under vacuum. The surface area $\left(\mathrm{S}_{\mathrm{BET}}\right)$ and total pore volume $\left(\mathrm{V}_{\mathrm{P}}\right)$ were calculated from the $\mathrm{N}_{2}$ adsorption isotherm. The micropore volume $\left(\mathrm{V}_{\text {Micro-NLDFT }}\right)$ and pore size distribution (PSD) were evaluated with the 2D-NLDFT-HS model, and considering that the surface of the carbon pores was heterogeneous (Jagiello and Olivier 2013b). The adsorption isotherms of $\mathrm{CO}_{2}$ were measured in a volumetric analyzer (Tristar 3020, Micromeritics) at $273 \mathrm{~K}$. The narrow microporosity $\left(\mathrm{W}_{0}\right)$ was evaluated by fitting the DubininRadushkevich equation to the adsorption isotherm data of $\mathrm{CO}_{2}$, and the Stoeckli and Ballerini (1991) equation was applied to estimate the average micropore width $\left(\mathrm{L}_{0}\right)$. The experimental isotherms were recorded in duplicates with an accuracy of ca. $2 \%$. The standard deviations 
associated to the calculation of the textural parameters from the experimental data were below $2 \%$. Here, average data is presented.

Raman spectroscopy was performed by excitation with green laser light $(532 \mathrm{~nm})$ in the range between $800-3550 \mathrm{~cm}^{-1}$. The spectra were acquired in a Jobin-Yvon Horiba HR800 spectrometer equipped with a Leica microscope. The acquisition time for each spectrum was 300 $\mathrm{s}$; to guarantee a representative sampling, spectra were recorded in 4 different spots for each sample. The temperature programmed desorption experiments (TPD) were carried out in a

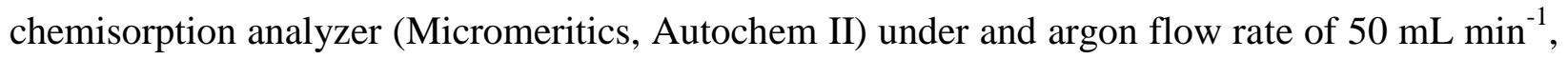
at a heating rate of $10{ }^{\circ} \mathrm{C} \mathrm{min}-1$ up to a final temperature of $1000{ }^{\circ} \mathrm{C} . \mathrm{CO}$ and $\mathrm{CO}_{2}$ evolution was monitored by mass spectrometry (OmniStar 3000). Data was performed in duplicates (average date is presented), with an with an accuracy of ca. $5 \%$.

\subsection{Adsorbate}

Diclofenac sodium salt was provided by Sigma-Aldrich. The molecular structure and physicochemical properties of this anti-inflammatory are shown in Table 1. The density functional theory (DFT) was applied to obtain the molecular structure of DCF (Moral-Rodríguez et al. 2016).

\subsection{Experimental adsorption equilibrium data}

In this work, the DCF solutions were fixed by adding a given aliquot of a DCF stock solution into a volumetric flask $(50 \mathrm{~mL})$ and then, diluting using a solution having a constant ionic strength of $0.01 \mathrm{~N}$ and $\mathrm{pH}$ of 7, 9 or 11 . The latter was made by mixing suitable volumes of $0.01 \mathrm{~N} \mathrm{HCl}$ and $\mathrm{NaOH}$ solutions. The DCF solution was sampled, and the sample $(10 \mathrm{~mL})$ was 
later analyzed to confirm the initial concentration of DCF, which varied from 400 to $2000 \mathrm{mg} / \mathrm{L}$. The concentration of DCF in water samples was quantified by a UV-Visible spectrophotometric method, and the absorbance of DCF in an aqueous solution was measured in a spectrophotometer, Shimadzu UV 2600, at a wavelength of $276 \mathrm{~nm}$.

An experimental batch adsorber was used to obtain the adsorption equilibrium data of DCF on ACs. A specific mass of the AC (25 mg) and volume of DCF solution (40 mL) were added in a centrifugal vial $(50 \mathrm{~mL})$, which was the batch adsorber. Thereupon, the vial was partially immersed in a thermostatic bath. The adsorbent and the solution were allowed to equilibrate during 7 days. Once the experiments reached equilibrium, an aliquot $(10 \mathrm{~mL})$ was sampled, and the concentration of DCF at equilibrium was quantified by the method explained previously. The $\mathrm{pH}$ of the solution in the adsorber was determined periodically during the adsorption experiment, and was maintained constant at a given value by the addition of few drops of $0.01 \mathrm{M} \mathrm{HCl}$ y $\mathrm{NaOH}$ solutions. Changes in the adsorber solution volume due to $\mathrm{pH}$ adjustment were considered negligible because they were less than $1.0 \%$.

The uptake of DCF adsorbed on the ACs was computed by carrying out a mass balance, which is represented by the subsequent mathematical expression:

$$
q=\frac{V\left(C_{0}-C_{e}\right)}{m}
$$

Where $\mathrm{q}$ is the mass of DCF adsorbed on $\mathrm{AC}, \mathrm{mg} / \mathrm{g} ; \mathrm{C}_{0}$ is the initial concentration of DCF, $\mathrm{mg} / \mathrm{L} ; \mathrm{C}_{\mathrm{e}}$ is the concentrattion of DCF at equilibrium, $\mathrm{mg} / \mathrm{L} ; \mathrm{m}$ is the mass of $\mathrm{AC}, \mathrm{g}$; and $\mathrm{V}$ is the solution volume in the adsorber, L. The error associated to the determination of DCF was found to be lower than $1.5 \%$, assuring that the deviations in the estimation of the uptake are lower than $4 \%$ in all cases. 
The adsorption of DCF in the effluent from a WWTP was carried out to study the actual application of the F and F40 for removing DCF. The adsorption of DFC was determined by contacting the ACs with a solution prepared by spiking DCF in a sample of an effluent from a WWTP situated in the city of San Luis Potosí, SLP, Mexico. The initial and equilibrium concentrations of DCF, TC and TOC in the solution were quantified as explained earlier. The pH of the wastewater solution was not adjusted nor maintained constant during the adsorption of DCF.

\subsection{Quantification of Total Organic Carbon}

The total carbon (TC), the inorganic carbon (IC) and the total organic carbon (TOC) of water samples were determined in a TOC analyzer, Shimadzu TOC-L, equipped with an autosampler ASI-L. The TC was measured by injecting a water sample into the reaction chamber packed with an oxidizing catalyst, and the oxidation of TC (organic and inorganic carbon) generated $\mathrm{CO}_{2}$ at $\mathrm{T}=680{ }^{\circ} \mathrm{C}$. Then, the $\mathrm{IC}$ was evaluated by injecting the sample into the chamber containing phosphoric acid. Under acidic conditions, the organic carbon was not oxidized, and the IC was converted into $\mathrm{CO}_{2}$. The difference between the TC and IC resulted in the TOC. The experimental error in TOC analysis was lower than 5\% (average data is presented).

\section{RESULTS AND DISCUSSION}

\subsection{Variation of the ACs properties with the activation time}

The primary purpose of this work was to ascertain the optimal porous properties of ACs for removing DCF from aqueous solution. The pristine $\mathrm{AC}$ was modified to enhance its porosity 
and enable access to the internal surface area, to maximize its adsorption capacity towards DCF. The pristine $\mathrm{AC}$ was subjected to physical activation with $\mathrm{CO}_{2}$ during varying activation times.

The adsorption isotherms of $\mathrm{N}_{2}$ of the four ACs at $77 \mathrm{~K}$ are depicted in Fig. 1(a), and based upon IUPAC classification (Rouquerol et al. 2014), the shapes of the adsorption isotherm were representative of type Ia for F, F12 and F24, that is typical of greatly microporous ACs with a distribution of micropore sizes mainly below $1 \mathrm{~nm}$. In contrast, sample F40 showed an isotherm of type Ib featuring a wide knee at low relative pressures, typical of materials having larger micropores and narrow mesopores. The opening of the isotherm knee and the total volume of $\mathrm{N}_{2}$ adsorbed increased gradually with the activation time, which was attributed to the widening of pore size and the enlargement of the micropore volume during the activation.

The principal textural properties of the ACs are listed in Table 2, and all these properties increased with the activation time. It can be noted that the $S_{\mathrm{BET}}$ of $\mathrm{F} 40$ carbon increased almost 2.3 times compared to the $\mathrm{S}_{\mathrm{BET}}$ of $\mathrm{F}$ carbon. Additionally, the values of $\mathrm{V}_{\mathrm{P}}, \mathrm{W}_{0}, \mathrm{~V}_{\text {Micro }}$ and $\mathrm{L}_{0}$ for F carbon were more than doubled after 40 hours of activation.

The $\mathrm{N}_{2}$ adsorption-desorption isotherm was interpreted with the 2D-NLDFT-HS model (Jagiello and Olivier 2013a) to evaluate the PSD of all the ACs (See Fig. 1(b)). This figure corroborates the formation and widening of the large micropores $\left(0.7 \mathrm{~nm}>\mathrm{d}_{\mathrm{p}}>2 \mathrm{~nm}\right)$ for F12, F24 and F40 carbons as the activation time progressed. Notably, the increase in the micropores in the range of 1-2 $\mathrm{nm}$ was more pronounced for F40 carbon. The micropore volume of F40 carbon $\left(\mathrm{V}_{\text {Micro, }}, \mathrm{W}_{\mathrm{o}, \mathrm{N} 2}\right.$ and $\left.\mathrm{W}_{\mathrm{o}, \mathrm{CO} 2}\right)$ was almost twice that of $\mathrm{F}$ carbon (See Table 2), confirming the development of microporosity along the activation time.

Additionally, the adsorption isotherms of $\mathrm{CO}_{2}$ were determined to evaluate the narrow microporosity of the ACs (Garrido et al. 1987; Contreras et al. 2010) at $273 \mathrm{~K}$, and are graphed 
in Fig. 2, showing the development of micropores as the activation time increased. At low relative pressures less than 0.010 , the volume of $\mathrm{CO}_{2}$ adsorbed on $\mathrm{F} 12$ and $\mathrm{F} 40$ carbons was lower than that on the pristine carbon, confirming the enlargement of the narrow micropores with the activation time. Moreover, the volume of $\mathrm{CO}_{2}$ adsorbed on F40 was less than that of F24, indicating that the narrow microporosity decreased at the expense of increasing the total micropore volume. The adsorption isotherm of $\mathrm{CO}_{2}$ on the pristine carbon intersects those on the modified carbons, demonstrating that the activation favors the enlargement of the micropores. The changes in the porosity did not have an impact in the structure of the series of carbons, as inferred from Raman spectroscopy (Figure Sx in the Supporting File).

Regarding the chemical composition, the successive activation of the carbons barely modified their composition, as can be inferred from the values of the elemental analysis listed in Table 3. The carbon content in all the ACs is higher than $95 \mathrm{wt} . \%$, whereas that of oxygen is less than 4 wt.\%. The oxygen content increases slightly with the activation time; however, the low oxygen contents reveal that all ACs have a minimal quantity of O-surface groups. This was quantification of the $\mathrm{CO}$ and $\mathrm{CO}_{2}$-evolving groups determined by TPD-MS (Table 3), and the evolution of the $\mathrm{pH}$ of the point of zero charge upon activatin, rendering carbons with a slightly more basic character.

In sum, the characterization results confirmed that the activation time with $\mathrm{CO}_{2}$ only provoked changes in the porosity of thecarbons, with no signification influence on the structure and chemical nature of the carbon surface.

\subsection{Diclofenac adsorption isotherms}


The experimental adsorption equilibrium data of DCF on the ACs were interpreted by the Radke-Prausnitz (R-P) isotherm model. This isotherm model was selected because, as argued later, the isotherm shape of $\mathrm{F}$ carbon was different from the isotherm shapes of the modified carbons. Besides, the R-P isotherm combines the characteristics of the Freundlich and Langmuir isotherms. The R-P model can be expressed by the subsequent equation:

$$
q=\frac{a C}{1+b C^{\beta}}
$$

where $a\left(\mathrm{~L} \mathrm{~g}^{-1}\right), \mathrm{b}\left(\mathrm{L}^{\beta} \mathrm{mg}^{-\beta}\right)$ and $\beta$ are the isotherm constants.

The R-P isotherm model was fitted to the experimental data, and the isotherm constants were computed by a regression method employing the nonlinear algorithm of RosenbrockNewton. The isotherm parameters and the values of the average percentage deviations (\%D) are given in Table 4. The subsequent equation was applied to estimate \%D:

$$
\% D=\left(\frac{1}{N} \sum_{i=1}^{N}\left|\frac{q_{\text {exp }}-q_{\text {pred }}}{q_{\text {exp }}}\right|\right) \times 100 \%
$$

Where $\mathrm{N}$ is the number of experimental data; $\mathrm{q}_{\exp }$ is the experimental uptake of DCF adsorbed, $\mathrm{mg} / \mathrm{g}$; and $\mathrm{q}_{\mathrm{pred}}$ is the uptake of DCF adsorbed estimated by the R-P isotherm model, $\mathrm{mg} / \mathrm{g}$. The R-P model fitted the experimental data satisfactorily because the $\% \mathrm{D}$ varied from 0.18 to $9.34 \%$.

The adsorption isotherms of DCF on F, F12, F24 and F40 carbons at $25{ }^{\circ} \mathrm{C}$ and $\mathrm{pH}$ of 7 are depicted in Fig. 3, and significant differences can be noticed on both the isotherm shapes and adsorption capacities of four carbons. The adsorption isotherms on all modified carbons show a Langmuir-type isotherm with a steep rise at low concentrations of DCF and leveling off at equilibrium concentrations of DCF greater than $1200 \mathrm{mg} / \mathrm{L}$. This behavior is characteristic of adsorbents having energetically homogeneous surfaces. For carbon F, the trend of adsorption equilibrium data of DCF was different, and the uptake of DCF increases by raising the 
concentration of DCF and does not level off or reach a plateau even at concentrations of DCF at equilibrium as high as $1500 \mathrm{mg} / \mathrm{g}$. This behavior is commonly observed in materials showing energetically heterogeneous surface. Thus, the surfaces of the modified carbons are more energetically homogenous than the surface of the pristine carbon.

\subsection{Influence of the activation time on the AC capacity for adsorbing DCF}

As illustrated in Fig. 3, the capacity of the ACs for adsorbing DCF from aqueous solution was considerably affected by the activation time and the decreasing order of the adsorption capacities was as follows: F40 > F24 > F12 > F. As shown in this figure, the maximum experimental adsorption capacities of F40, F24, F12, and F carbons were 1033, 821, 522 and 271 $\mathrm{mg} / \mathrm{g}$, correspondingly. A comparison of the adsorption capacities of all ACs can be performed by estimating the uptake of DCF adsorbed at an equilibrium concentration of DCF of $1200 \mathrm{mg} / \mathrm{L}$, and these values are referred to as $\mathrm{Q}_{1200}$. The concentration of $1200 \mathrm{mg} / \mathrm{L}$ was chosen as the value closest to the maximum uptake where experimental data is available for all the carbons. The values of $\mathrm{Q}_{1200}$ were predicted from the R-P adsorption models and are listed in Table 4. Analyzing the vales of $\mathrm{Q}_{1200}$, the adsorption capacities of F12, F24, and F40 carbons were enhanced $2.15,2.85$ and 3.85 times as a result of the activation time. This enhancement can be primarily attributed to the modification of the textural properties that favored the adsorption capacity by increasing the surface area and widening of the pore size. Comparable findings have been previously presented throughout the literature for the adsorption of organic compounds on ACs (Mestre et al. 2009; Nowicki et al. 2015).

The relationship between the adsorption capacity of ACs towards DCF and the textural properties was further studied by plotting the maximum adsorption capacity $\left(\mathrm{Q}_{1200}\right)$ versus the 
surface area, $\mathrm{S}_{\mathrm{BET}}$, and the results are shown in Fig. 4(a). As expected, $\mathrm{Q}_{1200}$ increased almost linearly concerning $\mathrm{S}_{\mathrm{BET}}$, and this tendency can be due to that the capacity of ACs for adsorbing organic compounds is highly affected by the magnitude of $\mathrm{S}_{\mathrm{BET}}$. The effect of $\mathrm{S}_{\mathrm{BET}}$ on $\mathrm{Q}_{1200}$ can be incorporated by recalculating the uptake per unit of surface area using the following equation:

$$
\mathrm{U}_{\mathrm{Norm}}=\frac{\mathrm{Q}_{1200}}{\mathrm{~S}_{\mathrm{BET}}}
$$

where, $U_{\text {Norm }}$ is the normalized uptake of DCF per unit of surface area, $\mathrm{mg} / \mathrm{m}^{2}$.

The dependence of $\mathrm{U}_{\text {Norm }}$ on the pore volumes $\left(\mathrm{V}_{\mathrm{P}}\right.$ and $\left.\mathrm{V}_{\text {Micro }}\right)$ and average micropore width $\left(\mathrm{L}_{0}\right)$ is also illustrated in Fig. $4(\mathrm{~b}-\mathrm{d})$, and as seen in these figures, $\mathrm{U}_{\text {Norm }}$ varied similarly concerning the textural properties $\mathrm{V}_{\mathrm{p}}, \mathrm{V}_{\text {Micro }}$ and $\mathrm{L}_{0}$. Furthermore, it can be observed that $\mathrm{U}_{\mathrm{Norm}}$ increases slightly and almost linearly for the F, F12 and F24 carbons, $\mathrm{U}_{\text {Norm }}$ reached a maximum value for F24 carbon, and then $\mathrm{U}_{\text {Norm }}$ was reduced for F40 carbon. It is essential to mention that the value of $U_{\text {Norm }}$ increased with the activation time for the ACs with average micropore width ranging between 1.4 and $1.6 \mathrm{~nm}$, but $\mathrm{U}_{\mathrm{Norm}}$ for $\mathrm{F} 40$ carbon dropped when the micropores are widened over this range. This trend reveals that the longer activation times do not favor the adsorption capacity and the critical role of the pore dimensions on the adsorption capacity.

Although $\mathrm{Q}_{1200}$ raised as a result of increasing the pore volume and surface area of ACs, the decrease in $\mathrm{U}_{\mathrm{Norm}}$ for F40 carbon demonstrated that the porosity of F24 carbon was more effectively utilized than that of F40 carbon (see Fig. 4(b-d)). For application purposes, the F24 carbon represents the most viable option, taking into account the costs associated with the additional activation time required for synthesizing F40 carbon. This result indicates that F24 carbon is the material whose activation conditions optimized the textural properties for removing DCF efficiently from water solutions. 


\subsection{Dependence of the adsorption capacity on the solution $\mathrm{pH}$}

The solution $\mathrm{pH}$ can dramatically influence the capacity of ACs for adsorbing ionizable compounds, as it may affect the charge of the AC surface and the species of DCF existing in aqueous solution. The effect of the solution $\mathrm{pH}$ on the capacity of F40 carbon for adsorbing DCF was examined by determining the adsorption isotherms at $\mathrm{pH}$ of 7,9 and 11. Experimental adsorption equilibrium data was not procured at $\mathrm{pH}$ below 6 because of the low solubility of DCF. A white solid was formed in a DCF solution when the solution pH was reduced below 6 . Carbon F40 was chosen because it presented the largest uptake and the highest concentration of functional groups containing oxygen (Table 2). The corresponding adsorption isotherms are depicted in Fig. 5, showing a remarkable reduction in the uptake of DCF adsorbed by raising the solution $\mathrm{pH}$ from 7 to 11 .

In accordance to the speciation diagram of DCF in aqueous solution (Fig. 6), the DCF can predominantly be as a non-ionizable molecule at $\mathrm{pH}<2$, and as an anionic or deprotonated species at $\mathrm{pH}>6$. In this work, the anionic molecule $\left(\mathrm{DCF}^{-}\right)$was the only species present because all the experiments were conducted at $\mathrm{pH}>6$. Furthermore, the solution $\mathrm{pH}$ also affected the surface charge of the nanoporous ACs. The $\mathrm{pH}_{\mathrm{PZC}}$ of the ACs varied within the range 8.5-9.2 (Table 2), so that the surface of the ACs had a positive charge at $\mathrm{pH}=7$, and negative at $\mathrm{pH}=11$. At $\mathrm{pH}=7$, the $\mathrm{DCF}^{-}$species were attracted to the surface of ACs whereas there was repulsion between the $\mathrm{DCF}^{-}$species and the surface of $\mathrm{ACs}$ at $\mathrm{pH}=11$. Thus, the adsorption capacity was lessened by increasing the solution $\mathrm{pH}$. This result can be explained recalling that the adsorption capacity was favored by the electrostatic attraction at $\mathrm{pH}=7$ and was diminished by the electrostatic repulsion at $\mathrm{pH}=11$. 
The reduction of the adsorption capacity for F40 caused by increasing the solution $\mathrm{pH}$ was evaluated by comparing $\mathrm{Q}_{1200}$ estimated at $\mathrm{pH}$ of 7, 9 and 11 . The values of $\mathrm{Q}_{1200}$ for $\mathrm{F} 40$ carbon at $\mathrm{pH} \mathrm{7,9}$ and 11 are given in Table 4. Thus, the adsorption capacity of F40 was reduced approximately 1.37 and 1.78 times by increasing the solution $\mathrm{pH}$ from 7 to 9 , and from 7 to 11 , correspondingly. The magnitude of this decrease in adsorption capacity indicates that the electrostatic interactions contributed significantly to the adsorption mechanism of the anionic species of DCF.

\subsection{Adsorption mechanism of DCF}

It is very well documented that the aromatic compounds can be predominantly adsorbed on ACs by the dispersive interactions due to $\pi$-electrons of the aromatic ring of the organic compound and $\pi$-electrons of the graphene layers of the ACs (Coughlin and Ezra 1968). The $\pi-\pi$ dispersive interactions are highly affected by the surface area and accessibility to surface area. Indeed, the activation of a carbon adsorbent increases the number of graphene layers available, while the widening of the micropore width ensures the accessibility to the surface area. The adsorption capacity of the ACs raised almost linearly by increasing the surface area, corroborating that the dispersive interactions significantly influenced the adsorption of DCF on ACs. Furthermore, the adsorption capacity of ACs may be favored or disfavored by the

electrostatic interactions between the ACs surface charge and the DCF species present in water solution.

\subsection{Comparison of adsorption capacities of carbon materials}


The maximum adsorption capacities of $\mathrm{F}$ carbon series were compared to those of other carbonaceous adsorbents published throughout the literature, and the maximum capacities for adsorbing DCF are listed in Table 5. The comparison was only among carbon-based materials because these materials usually exhibit high adsorption capacities towards organic compounds from water solution. Many different types of carbon materials have been investigated for adsorbing DCF from aqueous solutions, among these materials are activated carbons and biochars from various precursors, graphene oxide, expanded graphite, xerogels and carbon nanotubes. As shown in Table 5, the adsorption capacities of herein modified carbons are larger than those for the other carbon-based materials reported in previous works. The adsorption capacity of F40 was twice those of a porous carbon synthesized by pyrolyzing of metal azolate framework-6 (MAF-6) (An et al. 2018), and graphene oxide Nam et al. (2015), and about three times that of an AC commercially known as F400 (Moral-Rodríguez et al. 2016). Thus, the F40 presented the highest capacity of all carbonaceous adsorbents reported throughout the literature so far.

The capacity of each AC was normalized by dividing it by its surface area, and the adsorption capacity per unit of surface area was also listed in Table 5. Again, the DCF adsorption capacities of F40, F24 and F12 per unit surface area outperformed those of other carbon materials reported in the literature. The normalized adsorption capacity of F24 was nearly 4 times that of MAF-6 carbon, and the normalized capacity of the commercial activated carbon F400 is slightly greater than that of carbon F. The adsorption capacity per unit surface area is highly dependent on the accessibility of DCF to the pores of the carbon materials. Greater normalized adsorption capacity means that the surface area of the adsorbent is more efficiently 
used for adsorbing DCF. All the above findings show the paramount importance of tailoring the textural properties of the ACs for achieving an elevated uptake of DCF.

\subsection{Removal of DCF from a sample of water effluent from a WWTP}

The effect of the water matrix upon the capacity of the F and F40 carbons for adsorbing DCF was investigated by removing DCF from the effluent of a WWTP. The solution of DCF was prepared by spiking DCF in an effluent sample from a municipal WWTP, and the dosage of ACs was $1.25 \mathrm{~g} / \mathrm{L}$. The adsorption isotherms of DCF on the F and F40 carbons from the water sample of WWTP are depicted in Fig. 7. Besides, the Radke-Prausnitz isotherm modeled the adsorption equilibrium data of DCF from WWTP, and the values of \%D and adsorption isotherm constants are included in Table 4.

As seen in Fig. 7, the capacities of F and F40 carbons for adsorbing DCF were reduced in the WWTP solution. The values of $\mathrm{Q}_{1200}$ for carbons $\mathrm{F}$ and F40 in the WWTP solution were estimated to be 129 and $679 \mathrm{mg} / \mathrm{g}$, respectively (See Table 4), and comparing these results with those in the buffer solution at $\mathrm{pH}=7$, it can be noticed that the $\mathrm{Q}_{1200}$ of the $\mathrm{F}$ and $\mathrm{F} 40$ carbons were decreased $47.1 \%$ and $27.8 \%$. This result was somewhat expected because the effluent of a WWTP contains several inorganic and organic compounds, which may compete with the DCF for the adsorption sites of F and F40 ACs. The higher decrease of the adsorption capacity of carbon $\mathrm{F}$ than that of F40 could be attributed the narrow porosity of carbon $\mathrm{F}$, which would be clogged up more easily upon adsorption of other organic pollutants present in the WWTP.

The application of the F40 carbon in WWTP was studied by evaluating the removal of DCF, TC and OC by adsorption on F40 from the WWTP effluent sample for a DCF initial concentration of $674 \mathrm{mg} / \mathrm{L}$. The concentrations of DCF, TC and OC in the WWTP samples are 
given in Table 6, and the progress of other relevant water quality parameters (IC, $\mathrm{pH}$, conductivity and others) were also determined but were not reported in this work because their variation during adsorption was not crucial for removing of DCF. The percentage removal of DCF, TOC and OC were 77.7, 79.8 and $88.1 \%$, correspondingly. Consequently, the removal of DCF from WWTP solution can be effectively performed by adsorption on F40 carbon.

\section{CONCLUSIONS}

The adsorption capacity of ACs towards DCF from aqueous solutions was significantly affected by the porous structure of the ACs. The textural properties of the ACs were considerably modified by physical activation with $\mathrm{CO}_{2}$ during different times, and the surface area was raised, and the micropores were widened by increasing the activation time. The surface chemistry of the ACs was slightly modified by the physical activation with $\mathrm{CO}_{2}$, so differences in the adsorption capacity were mainly attributed to change in the textural properties of the ACs.

The adsorption capacities of ACs were enhanced by increasing the activation time. The adsorption capacities of the ACs increased almost linearly with the $\mathrm{S}_{\mathrm{BET}}, \mathrm{V}_{\mathrm{P}}, \mathrm{W}_{0}$ and $\mathrm{L}_{0}$. Furthermore, the maximum adsorption capacities of the modified ACs were well above those reported in the literature. The F24 carbon presented the highest normalized uptake of DCF adsorbed so that the F24 carbon had the optimal textural characteristics to remove DFC efficiently from aqueous solution. Consequently, the capacity of AC for adsorbing DCF can be maximized by the proper modification of its textural properties.

The capacity of ACs for adsorbing emerging pollutants can be considerably enhanced by tailoring the textural properties of the ACs. The concentration of DCF in a WWTP effluent was 
effectively reduced by adsorption on F40, attaining a percentage removal of $77.7 \%$ of this pollutant, along with a large removal of TOC and TC.

\section{ACKNOWLEDGMENTS}

This work was supported by Consejo Nacional de Ciencia y Tecnologia, CONACyT, Mexico (grants numbers INFR-2012-01-188381 and CB-2012-02-182779). COA and JBP thank the support of the Spanish MINECO (grant number CTM2014/56770-R).

\section{REFERENCES}

Álvarez S, Ribeiro RS, Gomes HT, Sotelo JL, García J (2015) Synthesis of carbon xerogels and their application in adsorption studies of caffeine and diclofenac as emerging contaminants. Chem Eng Res Des 95:229-238.

Álvarez Torrellas S, García Lovera R, Escalona N, Sepúlveda C, Sotelo JL, García J (2015) Chemical-activated carbons from peach stones for the adsorption of emerging contaminants in aqueous solutions. Chem Eng J 279:788-798.

Álvarez Torrellas S, Muñoz M, Zazo JA, Casas JA, García J (2016) Synthesis of high surface area carbon adsorbents prepared from pine sawdust-Onopordum acanthium L. for nonsteroidal anti-inflammatory drugs adsorption. J Environ Manage 183:294-305.

An HJ, Bhadra BN, Khan NA, Jhung SH (2018) Adsorptive removal of wide range of pharmaceutical and personal care products from water by using metal azolate framework-6 derived porous carbon. Chem Eng J 343:447-454.

Ania CO, Cabal B, Parra JB, Pis JJ (2007) Importance of the hydrophobic character of activated carbons on the removal of naphthalene from the aqueous phase. Ads Sci Technol 25: 155-168. 
Carvalho AP, Mestre AS, Haro M, Ania CO (2012) Advanced methods for the removal of acetaminophen from water in A. Javaherian, P: Latifpour (Eds) Acetaminophen, Properties, Clinical Uses and Adverse Effects, Nova Science Publishers Inc, New York, pp 57-105.

Carvalho AP, Mestre AS, Andrade M, Ania CO (2013) Ibuprofen in the aquatic environment: Occurrence, ecotoxicity and water remediation technologies, in: W.C. Carter, B.R. Brown (Eds) Ibuprofen: Clinical Pharmacology Medical Uses and Adverse Effects, Nova Science Publishers Inc, New York, pp 1-60.

Clara M, Strenn B, Gans O, Martinez E, Kreuzinger N, Kroiss H (2005) Removal of selected pharmaceuticals, fragrances and endocrine disrupting compounds in a membrane bioreactor and conventional wastewater treatment plants. Water Res 39:4797-807.

Cleuvers M (2003) Aquatic ecotoxicity of pharmaceuticals including the assessment of combination effects. Toxicol Lett 142:185-194.

Contreras MS, Páez CA, Zubizarreta L, Léonard A, Blacher S, Olivera-Fuentes CG, Arenillas A, Pirard JP, Job N (2010) A comparison of physical activation of carbon xerogels with carbon dioxide with chemical activation using hydroxides. Carbon 48:3157-3168.

Coughlin RW, Ezra FS (1968) Role of surface acidity in the adsorption of organic pollutants on the surface of carbon. Environ Sci Technol 2:291-297.

Daughton CG, Ternes TA (1999) Pharmaceuticals and personal care products in the environment: Agents of subtle change?. Environ Health Perspect 107:907-938.

De Franco MAE, de Carvalho CB, Bonetto MM, de Pelegrini Soares R, Féris LA (2018) Diclofenac removal from water by adsorption using activated carbon in batch mode and fixedbed column: Isotherms, thermodynamic study and breakthrough curves modeling. J Clean Prod 181:145-154. 
Garrido J, Linares- Solano A, Martin- Martinez JM, Molina-Sabio M, Rodriguez- Reinoso F, Torregrosa R (1987) Use of nitrogen vs. carbon dioxide in the characterization of activated carbons. Langmuir 3:76-81.

Gomis-Berenguer A, Iniesta J, Moro A, Maurino V, Lima JC, Ania CO (2016) Boosting visible light conversion in the confined pore space of nanoporous carbons, Carbon 96:98-104.

Houeto P, Carton A, Guerbet M, Mauclaire AC, Gatignol C, Lechat P, Masset D (2012) Assessment of the health risks related to the presence of drug residues in water for human consumption: Application to carbamazepine. Regul Toxicol Pharm 62:41-48.

Jagiello J, Olivier JP (2013a) Carbon slit pore model incorporating surface energetical heterogeneity and geometrical corrugation. Adsorption 19:777-783.

Jagiello J, Olivier JP (2013b) 2D-NLDFT adsorption models for carbon slit-shaped pores with surface energetical heterogeneity and geometrical corrugation. Carbon 55:70-80.

Jodeh S, Abdelwahab F, Jaradat N, Warad I, Jodeh W (2015) Adsorption of diclofenac from aqueous solution using Cyclamen persicum tubers based activated carbon (CTAC). J Association of Arab Univ for Basic and App Sci 20:32-38.

Jung C, Boateng LK, Flora JRV, Oh J, Braswell MC, Son A, Yoon Y (2015) Competitive adsorption of selected non-steroidal anti-inflammatory drugs on activated biochars: Experimental and molecular modeling study. Chem Eng J 264:1-9.

Kasprzyk-Hordern B, Dinsdale RM, Guwy AJ (2009) The removal of pharmaceuticals, personal care products, endocrine disruptors and illicit drugs during wastewater treatment and its impact on the quality of receiving waters. Water Res 43:363-380. 
Malhotra M, Suresh S, Garg A (2018) Tea waste derived activated carbon for the adsorption of sodium diclofenac from wastewater: adsorbent characteristics, adsorption isotherms, kinetics, and thermodynamics. Environ Sci Pollut Res. https://doi.org/10.1007/s11356-018-3148-y.

Mestre AS, Pires J, Nogueira JMF, Parra JB, Carvalho AP, Ania CO (2009) Waste-derived activated carbons for removal of ibuprofen from solution: Role of surface chemistry and pore structure. Bioresource Technol 100:1720-1726.

Moral-Rodríguez AI, Leyva-Ramos R, Ocampo-Pérez R, Mendoza-Barron J, Serratos-Alvarez IN, Salazar-Rabago JJ (2016) Removal of ronidazole and sulfamethoxazole from water solutions by adsorption on granular activated carbon: equilibrium and intraparticle diffusion mechanisms. Adsorption 22:89-103.

Nam SWD, Choi J, Kim SK, Her N, Zoh KD (2014) Adsorption characteristics of selected hydrophilic and hydrophobic micropollutants in water using activated carbon. J Hazard Mater 270:144-152.

Nam SW, Jung C, Li H, Yu M, Flora JRV, Boateng LK, Her N, Zoh K-D, Yoon Y (2015) Adsorption characteristics of diclofenac and sulfamethoxazole to graphene oxide in aqueous solution. Chemosphere 136:20-26.

Nowicki P, Kazmierczak J, Pietrzak R (2015) Comparison of physicochemical and sorption properties of activated carbons prepared by physical and chemical activation of cherry stones. Powder Technol 269:312-319.

Rakić V, Rac V, Krmar M, Otman O, Auroux A (2015) The adsorption of pharmaceutically active compounds from aqueous solutions onto activated carbons. J Hazard Mater 282:141-149. Rouquerol F, Rouquerol J, Sing KSW, Llewellyn P, Maurin G (2014) Adsorption by powders and porous solids: Principles, methodology and applications. Academic Press, London. 
Saucier C, Adebayo MA, Lima EC, Cataluña R, Thue PS, Prola LDT, Puchana-Rosero MJ, Machado FM, Pavan FA, Dotto GL (2015) Microwave-assisted activated carbon from cocoa shell as adsorbent for removal of sodium diclofenac and nimesulide from aqueous effluents. $\mathrm{J}$ Hazard Mater 289:18-27.

Stoeckli F, Ballerini L (1991) Evolution of microporosity during activation of carbon. Fuel 70:557-559.

Sotelo JL, Ovejero G, Rodríguez A, Álvarez S, Galán J, García J (2014) Competitive adsorption studies of caffeine and diclofenac aqueous solutions by activated carbon. Chem Eng J 240:443453.

Richards SM, Wilson CJ, Johnson DJ, Castle DM, Lam M, Mabury SA, Sibley PK, Solomon KR (2004) Effects of pharmaceutical mixtures in aquatic microcosms. Environ Toxicol Chem 23:1035-1042.

Rivera-Utrilla J, Prados-Joya G, Sánchez- Polo M, Ferro-García MA, Bautista-Toledo I (2009) Removal of nitroimidazole antibiotics from aqueous solution by adsorption/bioadsorption on activated carbon. J Hazard Mater 170:298-305.

Rúa-Gómez PC, Püttmann W (2012) Occurrence and removal of lidocaine, tramadol, venlafaxine, and their metabolites in German wastewater treatment plants. Environ Sci Pollut Res 19: 689-99.

Ternes TA (1998) Occurrence of drugs in German sewage treatment plants and rivers. Water Res $32: 3245-3260$.

Ternes TA, Meisenheimer M, McDowell D, Sacher F, Brauch H-J, Haist-Gulde B, Preuss G, Wilme U, Zulei-Seibert N (2002) Removal of pharmaceuticals during drinking water treatment. Environ Sci Technol 36:3855-3863. 
Vedenyapina MD, Borisova DA, Simakova AP, Proshina LP, Vedenyapin AA (2013) Adsorption of diclofenac sodium from aqueous solutions on expanded graphite. Solid Fuel Chem 47:59-63.

Watkinson JA, Murby EJ, Costanzo SD (2007) Removal of antibiotics in conventional and advanced wastewater treatment: Implications for environmental discharge and wastewater recycling. Water Res 41:4164-4176.

Wei H, Deng S, Huang Q, Nie Y, Wang B, Huang J, Yu G (2013) Regenerable granular carbon nanotubes/alumina hybrid adsorbents for diclofenac sodium and carbamazepine removal from aqueous solution. Water Res 47:4139-4147. 
Table 1. Molecular structure and physicochemical properties of DCF.

\begin{tabular}{|c|c|c|c|c|c|}
\hline Drug & Molecular structure & $\begin{array}{c}\text { Molecular } \\
\text { weight } \\
(\mathrm{g} / \mathrm{mol})\end{array}$ & $\begin{array}{c}\text { Size } \\
\mathrm{X}, \mathrm{Y}, \mathrm{Z} \\
(\AA)\end{array}$ & $\begin{array}{c}\log \\
\mathrm{K}_{\mathrm{Ow}}^{\mathrm{a}}\end{array}$ & $\mathrm{pKa}$ \\
\hline $\begin{array}{c}\text { Diclofenac } \\
\text { sodium } \\
\mathrm{C}_{14} \mathrm{H}_{10} \mathrm{C}_{12} \mathrm{NNaO}_{2} \\
(\mathrm{DCF})\end{array}$ & & 318.13 & $\begin{array}{l}X: 0.960 \\
Y: 0.708 \\
Z: 0.472\end{array}$ & $3.91^{\mathrm{b}}$ & 4.15 \\
\hline
\end{tabular}

${ }^{\text {a }}$ Octanol-water partition coefficient.

${ }^{\mathrm{b}} \mathrm{Nam}$ et al. (2014). 
Table 2. Textural properties of the F, F12, F24 and F40 carbons.

\begin{tabular}{cccccccc}
\hline $\begin{array}{c}\text { Activated } \\
\text { Carbon }\end{array}$ & $\begin{array}{c}\mathrm{S}_{\mathrm{BET}} \\
\left(\mathrm{m}^{2} / \mathrm{g}\right)\end{array}$ & $\begin{array}{c}\mathrm{V}_{\mathrm{P}}{ }^{\mathrm{a}} \\
\left(\mathrm{cm}^{3} / \mathrm{g}\right)\end{array}$ & $\begin{array}{c}\mathrm{V}_{\text {Meso }}{ }^{\mathrm{b}, \mathrm{c}} \\
\left(\mathrm{cm}^{3} / \mathrm{g}\right)\end{array}$ & $\begin{array}{c}\mathrm{V}_{\text {Micro }}{ }^{\mathrm{b}} \\
\left(\mathrm{cm}^{3} / \mathrm{g}\right)\end{array}$ & $\begin{array}{c}\mathrm{W}_{\mathrm{o}, \mathrm{N} 2}{ }^{\mathrm{c}} \\
\left(\mathrm{cm}^{3} / \mathrm{g}\right)\end{array}$ & $\begin{array}{c}\mathrm{L}_{0}{ }^{\mathrm{d}} \\
(\mathrm{nm})\end{array}$ & $\begin{array}{c}\mathrm{W}_{\mathrm{o}, \mathrm{CO} 2}{ }^{\mathrm{c}} \\
\left(\mathrm{cm}^{3} / \mathrm{g}\right)\end{array}$ \\
\hline $\mathrm{F}$ & 799 & 0.35 & 0.03 & 0.31 & 0.37 & 0.91 & 0.25 \\
$\mathrm{~F} 12$ & 1146 & 0.50 & 0.04 & 0.45 & 0.55 & 1.37 & 0.33 \\
$\mathrm{~F} 24$ & 1279 & 0.58 & 0.06 & 0.50 & 0.64 & 1.56 & 0.37 \\
$\mathrm{~F} 40$ & 1801 & 0.86 & 0.15 & 0.66 & 0.80 & 2.00 & 0.36 \\
\hline
\end{tabular}

a Total pore volume determined at $\mathrm{P} / \mathrm{P}^{0} \approx 0.99$.

${ }^{\mathrm{b}}$ Calculated from 2D-NLDFT-HS model (Jagiello and Olivier 2013b)

${ }^{c}$ Micropore volume calculated by the Dubinin-Radushkevich method.

${ }^{\mathrm{d}}$ Average micropore size evaluated by the Stoeckli-Ballerini equation. 
Table 3. Selected chemical paramters of the studied nanoporous carbons: Elemental analysis (wt.\%) on dry ash free basis, point of zero charge, and amount of $\mathrm{CO}$ and $\mathrm{CO}_{2}$ evolved from the materials upon TPD-MS.

\begin{tabular}{ccccccc}
\hline $\begin{array}{c}\text { Activated } \\
\text { Carbon }\end{array}$ & $\mathrm{C}($ wt.\%) & $\mathrm{H}($ wt.\%) & $\mathrm{O}($ wt.\%) & $\mathrm{pH}_{\mathrm{PZC}}$ & $\begin{array}{c}\mathrm{CO} \\
(\mathrm{mmol} / \mathrm{g})\end{array}$ & $\begin{array}{c}\mathrm{CO}_{2} \\
(\mathrm{mmol} / \mathrm{g})\end{array}$ \\
\hline $\mathrm{F}$ & 96.40 & 0.70 & 2.90 & 8.7 & 698 & 335 \\
$\mathrm{~F} 12$ & 96.12 & 0.45 & 3.43 & 8.5 & 517 & 238 \\
$\mathrm{~F} 24$ & 95.96 & 0.39 & 3.65 & 8.8 & 549 & 205 \\
$\mathrm{~F} 40$ & 96.04 & 0.22 & 3.74 & 9.2 & 589 & 158 \\
\hline
\end{tabular}


Table 4. Parameter values of the Radke-Prausnitz adsorption isotherms for adsorption of DCF from aqueous solution on the activated carbons. $\mathrm{T}=25^{\circ} \mathrm{C}$.

\begin{tabular}{|c|c|c|c|c|c|c|}
\hline $\begin{array}{c}\text { Activated } \\
\text { Carbon }\end{array}$ & $\mathrm{pH}$ & $\begin{array}{c}\mathrm{Q}_{1200} \\
(\mathrm{mg} / \mathrm{g})\end{array}$ & $\begin{array}{c}\mathrm{a} \\
(\mathrm{L} / \mathrm{g})\end{array}$ & $\begin{array}{c}\mathrm{b} \\
\left(\mathrm{L}^{\beta} \mathrm{mg}^{-\beta}\right)\end{array}$ & $\beta$ & $\% \mathrm{D}$ \\
\hline \multirow{2}{*}{$\mathrm{F}$} & 7 & 244 & 1.4 & 0.1 & 0.54 & 8.82 \\
\hline & WWTP & 129 & 0.5 & 0.001 & 1.08 & 8.86 \\
\hline F12 & 7 & 524 & 93.4 & 0.6 & 0.84 & 2.26 \\
\hline $\mathrm{F} 24$ & 7 & 696 & 768.7 & 3.4 & 0.84 & 8.13 \\
\hline \multirow{4}{*}{ F40 } & 7 & 940 & 836.7 & 2.71 & 0.84 & 9.34 \\
\hline & 9 & 686 & 371.4 & 0.8 & 0.95 & 3.90 \\
\hline & 11 & 528 & 625.7 & 2.3 & 0.91 & 3.96 \\
\hline & WWTP & 679 & 103.5 & 0.31 & 0.90 & 0.18 \\
\hline
\end{tabular}

* WWTP $=$ Water sample from a WasteWater Treatment Plant. 
Table 5. Maximum adsorption capacities of carbon materials towards DCF from aqueous solutions.

\begin{tabular}{|c|c|c|c|c|c|}
\hline Adsorbent & $\begin{array}{c}\text { Maximum } \\
\text { adsorption } \\
\text { capacity } \\
(\mathrm{mg} / \mathrm{g})\end{array}$ & $\begin{array}{c}\text { Adsorption } \\
\text { capacity per } \\
\text { surface area } \\
\left(\mathrm{mg} / \mathrm{m}^{2}\right)\end{array}$ & $\begin{array}{c}\mathrm{S}_{\mathrm{BET}} \\
\left(\mathrm{m}^{2} / \mathrm{g}\right)\end{array}$ & $\begin{array}{c}\text { Experimental } \\
\text { conditions }\end{array}$ & Reference \\
\hline $\mathrm{F} 40$ & 1033 & 0.574 & 1801 & \multirow{4}{*}{$\begin{array}{c}\mathrm{pH}=7 \\
\mathrm{~T}=25{ }^{\circ} \mathrm{C}\end{array}$} & \multirow{4}{*}{ This work } \\
\hline $\mathrm{F} 24$ & 821 & 0.642 & 1279 & & \\
\hline $\mathrm{F} 12$ & 522 & 0.455 & 1146 & & \\
\hline $\mathrm{F}$ & 271 & 0.339 & 799 & & \\
\hline $\begin{array}{l}\text { Porous Carbon } \\
\text { (Metal azolate } \\
\text { framework-6) }\end{array}$ & 503 & 0.161 & 3123 & $\mathrm{pH}=6.5$ & (An et al. 2018) \\
\hline $\begin{array}{l}\text { Graphene oxide } \\
\text { (GO) }\end{array}$ & 500 & -- & NA* & $\begin{array}{c}\mathrm{pH}=7 \\
\mathrm{~T}=20^{\circ} \mathrm{C}\end{array}$ & (Nam et al. 2015) \\
\hline $\begin{array}{l}\text { Activated biochar } \\
\text { (pine chip) }\end{array}$ & 373 & 0.274 & 1360 & $\begin{array}{c}\mathrm{pH}=7 \\
\mathrm{~T}=25^{\circ} \mathrm{C}\end{array}$ & (Jung et al. 2015) \\
\hline $\begin{array}{c}\text { Granular AC } \\
(\mathrm{F}-400)\end{array}$ & 347 & 0.378 & 919 & $\begin{array}{c}\mathrm{pH}=6 \\
\mathrm{~T}=25^{\circ} \mathrm{C}\end{array}$ & (Moral - Rodríguez 2014) \\
\hline $\begin{array}{l}\text { Expanded } \\
\text { graphite }\end{array}$ & 330 & -- & NA* & No specified & (Vedenyapina et al. 2013) \\
\hline $\begin{array}{l}\text { Activated carbon } \\
\text { (pine sawdust) }\end{array}$ & 263.7 & 0.331 & 796 & $\begin{array}{l}\mathrm{pH}=6.3 \\
\mathrm{~T}=30^{\circ} \mathrm{C}\end{array}$ & (Álvarez-Torrellas et al. 2016) \\
\hline $\begin{array}{c}\text { Granular AC } \\
(\mathrm{F}-400)\end{array}$ & 234 & 0.235 & 997 & $\begin{array}{l}\mathrm{pH}=6.3 \\
\mathrm{~T}=23^{\circ} \mathrm{C}\end{array}$ & (Sotelo et al. 2014) \\
\hline $\begin{array}{l}\text { Carbon xerogel } \\
\text { treated with } \\
\text { sulfuric acid }\end{array}$ & 80.0 & 0.278 & 288 & $\begin{array}{l}\mathrm{pH}=6.1 \\
\mathrm{~T}=30^{\circ} \mathrm{C}\end{array}$ & (Álvarez et al. 2015) \\
\hline $\mathrm{AC}($ cocoa shell $)$ & 63.47 & 0.103 & 619 & $\begin{array}{c}\mathrm{pH}=7 \\
\mathrm{~T}=25^{\circ} \mathrm{C}\end{array}$ & (Saucier et al. 2015) \\
\hline AC (Tea wate) & 62 & 0.072 & 865 & $\mathrm{~T} \approx 30^{\circ} \mathrm{C}$ & (Malhotra et al. 2018) \\
\hline Granular AC & 36.23 & 0.078 & 462.96 & $\begin{array}{c}\mathrm{pH}=5.5 \\
\mathrm{~T}=25^{\circ} \mathrm{C}\end{array}$ & (De Franco et al. 2018) \\
\hline $\mathrm{CNTs} / \mathrm{Al}_{2} \mathrm{O}_{3}$ & 29 & 0.122 & 237 & $\mathrm{pH}=6$ & (Wei et al. 2013) \\
\hline $\begin{array}{c}\text { AC (Cyclamen } \\
\text { persicum tubers) }\end{array}$ & 22 & 0.036 & 606.78 & $\begin{array}{c}\mathrm{pH}=2 \\
\mathrm{~T}=25^{\circ} \mathrm{C}\end{array}$ & (Jodeh et al. 2015) \\
\hline
\end{tabular}

$* \mathrm{NA}=$ No available. 
Table 6. Concentrations and removal percentages of DCF, TC and TOC before and after contacting the WWTP solution containing DCF with the F40 carbon.

\begin{tabular}{cccc}
\hline Sample & DCF & TC & TOC \\
& $(\mathrm{mg} / \mathrm{L})$ & $(\mathrm{mg} / \mathrm{L})$ & $(\mathrm{mg} / \mathrm{L})$ \\
\hline WWTP without spiking DCF & 0 & 31.9 & 2.41 \\
WWTP spiked with DCF & 674 & 289 & 267 \\
WWTP spiked with DCF after adsorption on F40 & 150 & 58.5 & 31.8 \\
Removal Percentage $(\%)$ & 78 & 80 & 88 \\
\hline
\end{tabular}




\section{List of Figure Captions}

Fig. 1. Adsorption-desorption isotherms of $\mathrm{N}_{2}$ on the nanoporous carbons at $77 \mathrm{~K}$ (a), and pore size distributions calculated using 2D-NLDFT-HS method (b).

Fig. 2. Adsorption isotherms of $\mathrm{CO} 2$ at $273 \mathrm{~K}$ on the nanoporous carbons.

Fig. 3. Adsorption isotherms of $\mathrm{DCF}$ on the $\mathrm{F}$ carbon series at $\mathrm{T}=25^{\circ} \mathrm{C}$ and $\mathrm{pH}=7$. The symbols represent the experimental data and the lines depict the prediction of the RadkePrausnitz isotherm.

Fig. 4. Effect of selected textural properties on the adsorption capacities of ACs towards DCF. a) $\mathrm{Q}_{1200}$ vs. $\mathrm{S}_{\mathrm{BET}}$, b) $\mathrm{U}_{\text {Norm }}$ vs. $\mathrm{V}_{\mathrm{P}}$, c) $\mathrm{U}_{\text {Norm }}$ vs. $\mathrm{V}_{\text {micro }}$, d) $\mathrm{U}_{\text {Norm }}$ vs. $\mathrm{L}_{0}$.

Fig. 5. Effect of solution $\mathrm{pH}$ on the adsorption isotherm of DCF on $\mathrm{F} 40$ at $\mathrm{T}=25{ }^{\circ} \mathrm{C}$. The symbols represent the experimental data and the lines depict the prediction of the RadkePrausnitz isotherm.

Fig. 6. Speciation diagram of DCF in aqueous solution as a function of the solution $\mathrm{pH}$.

Fig. 7. Effect of water matrix on the adsorption of DCF on $\mathrm{F}$ and $\mathrm{F} 40$ carbons at $\mathrm{T}=25^{\circ} \mathrm{C}$. The symbols represent the experimental data and the lines depict the prediction of the RadkePrausnitz isotherm. 


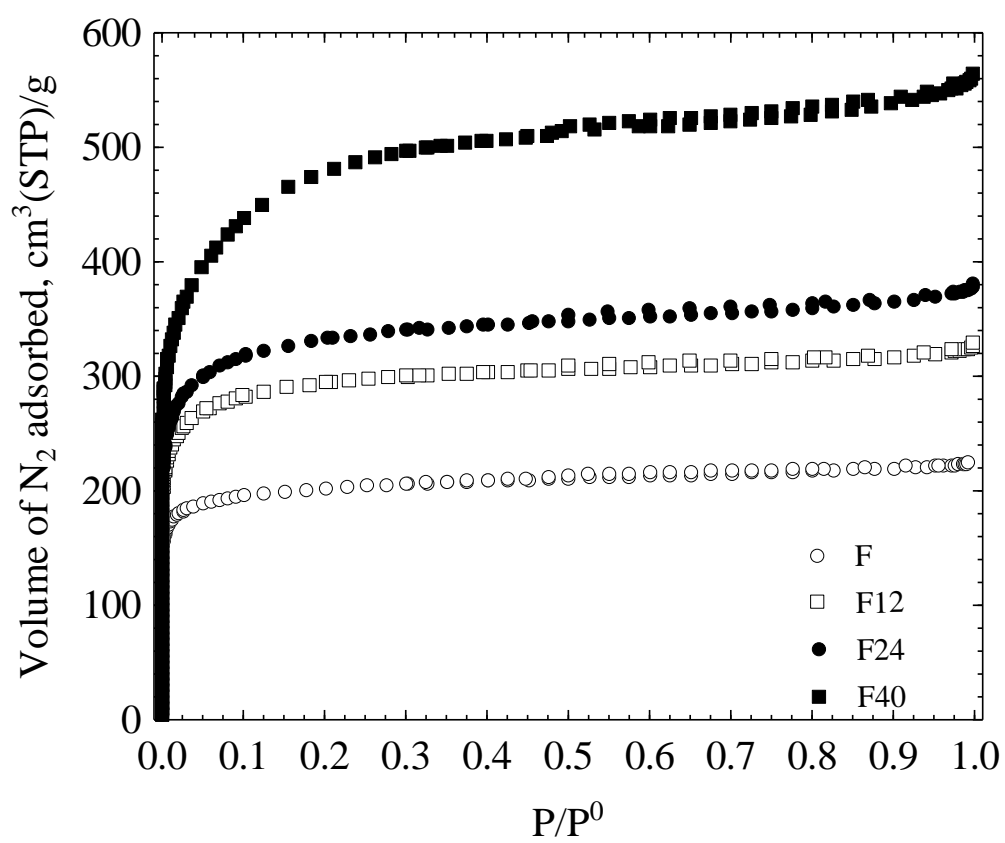

(a)

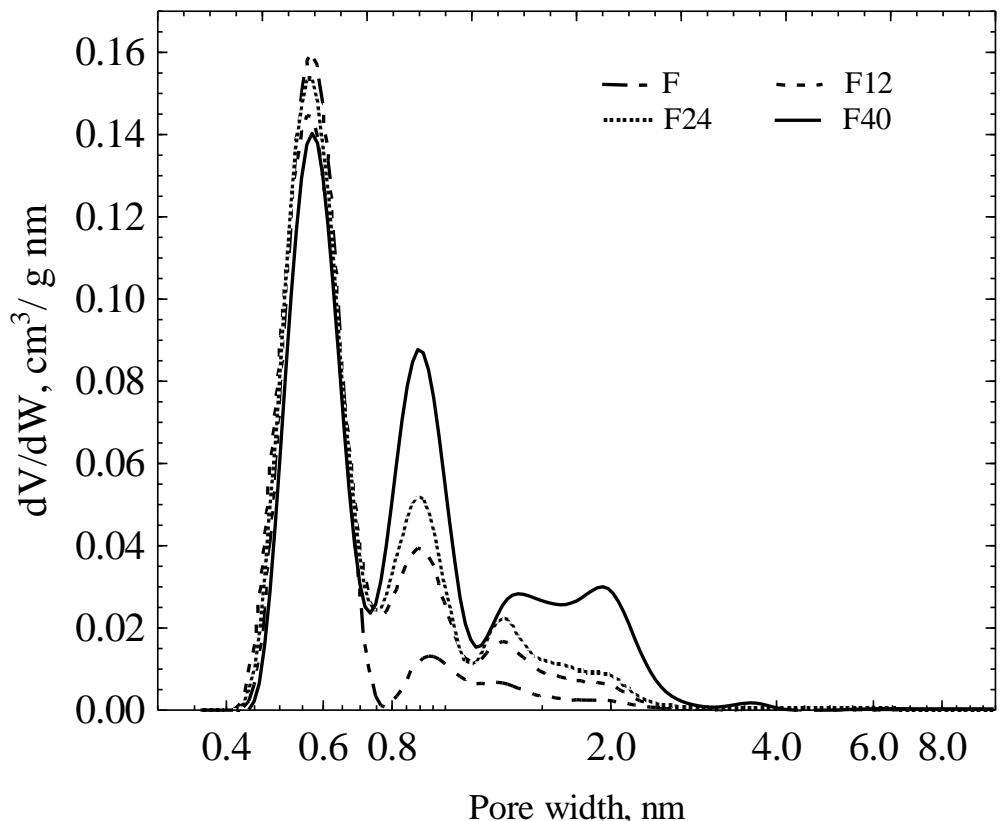

(b)

Fig. 1 


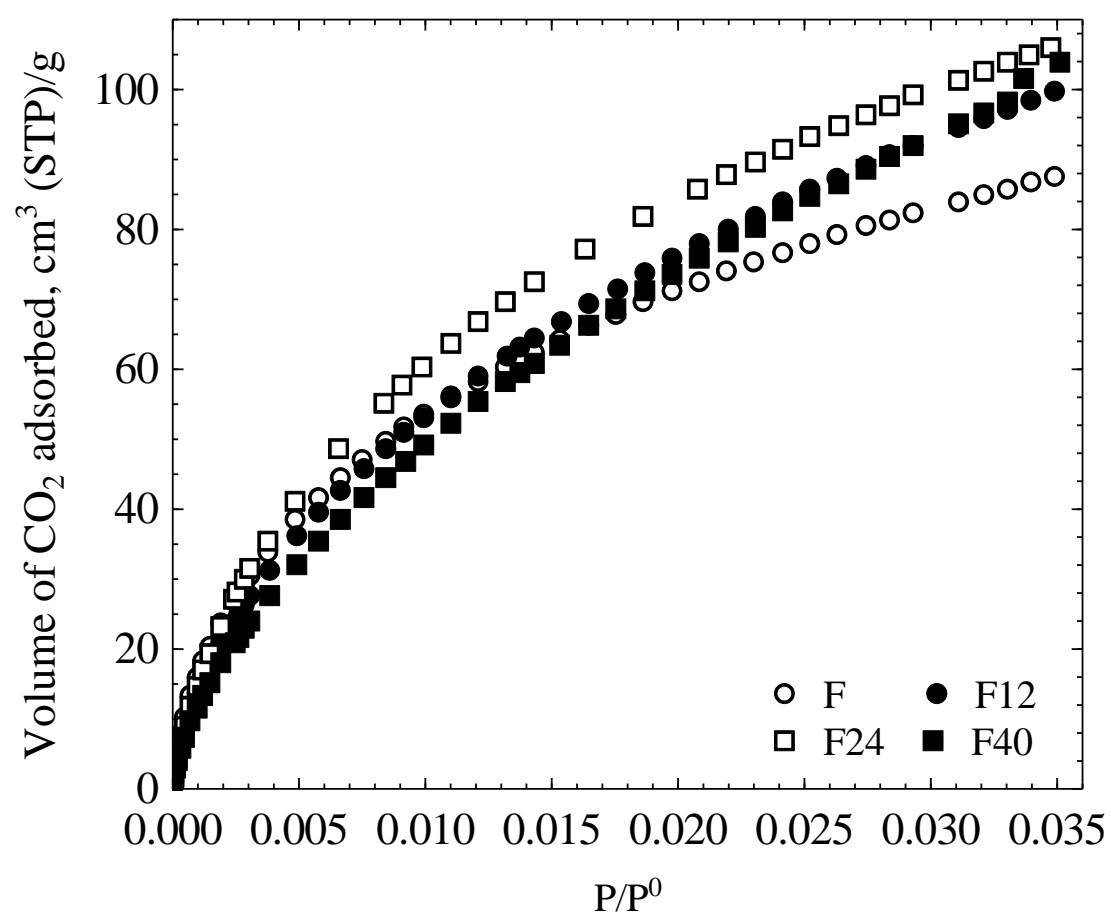

Fig. 2 


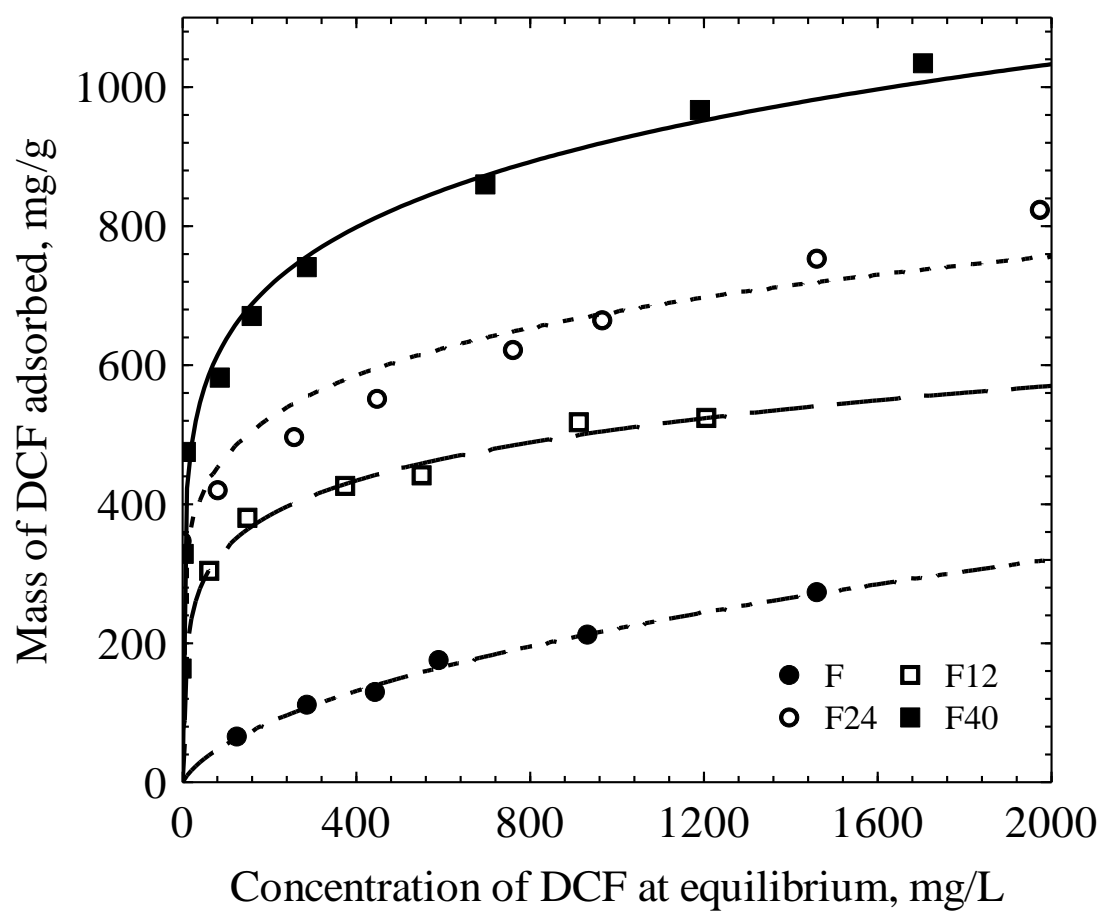

Fig. 3 


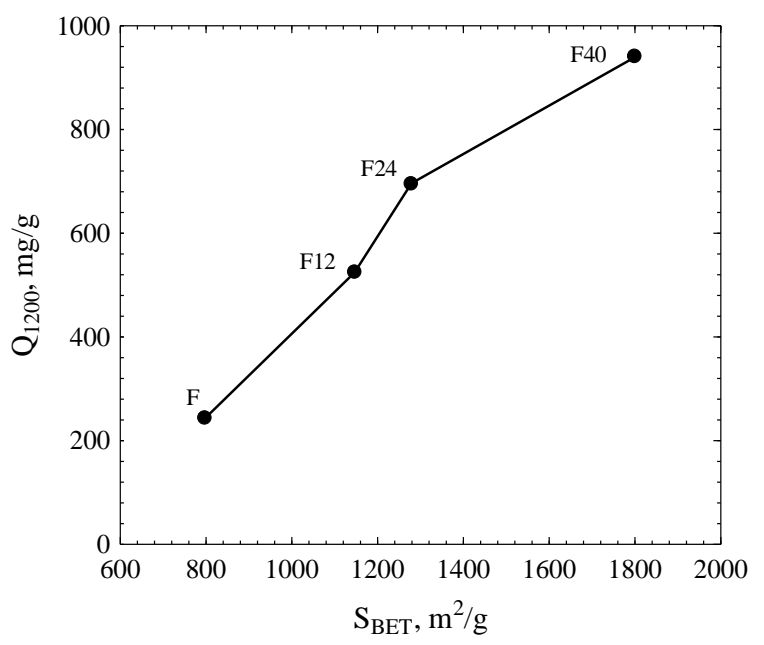

a)

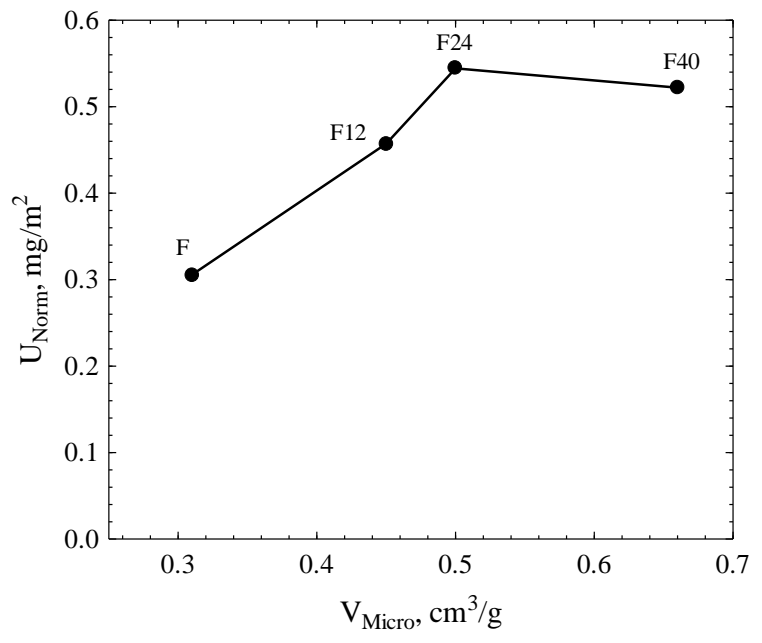

c)

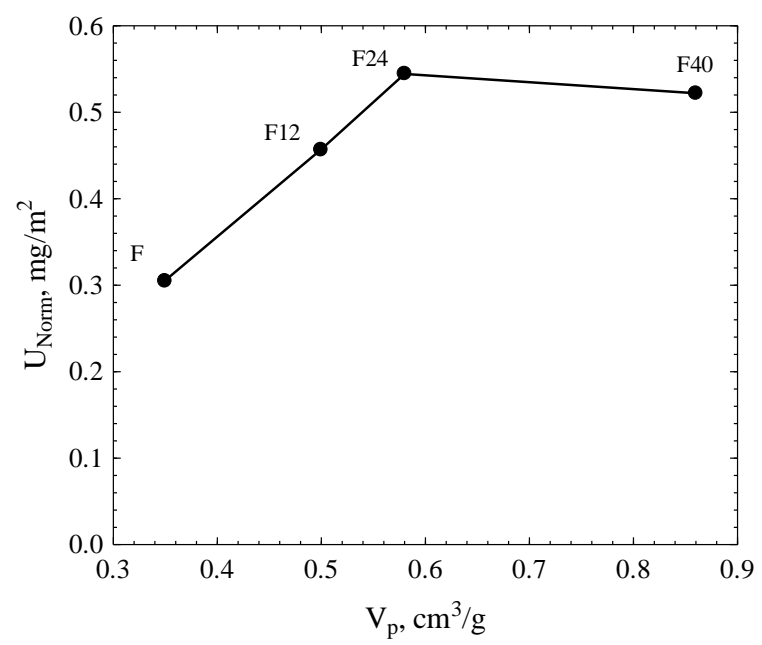

b)

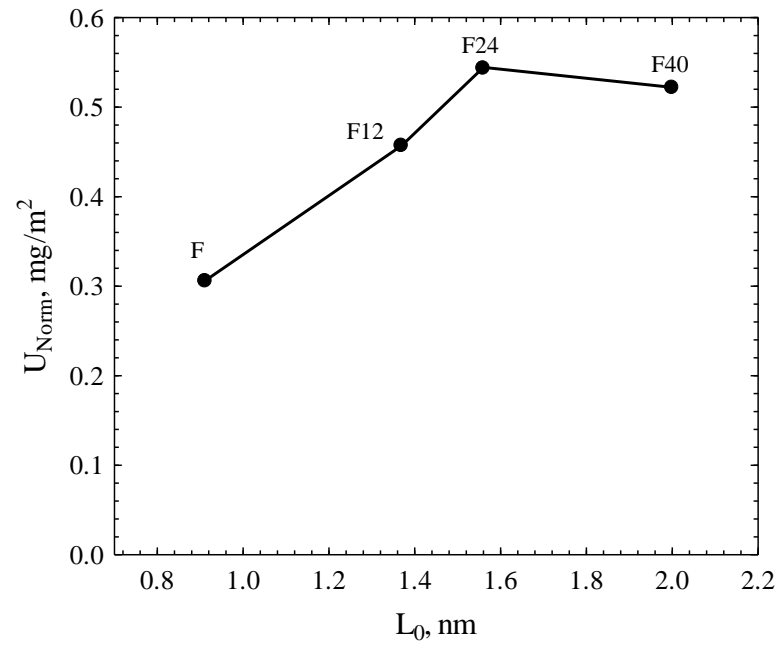

d)

Fig. 4 


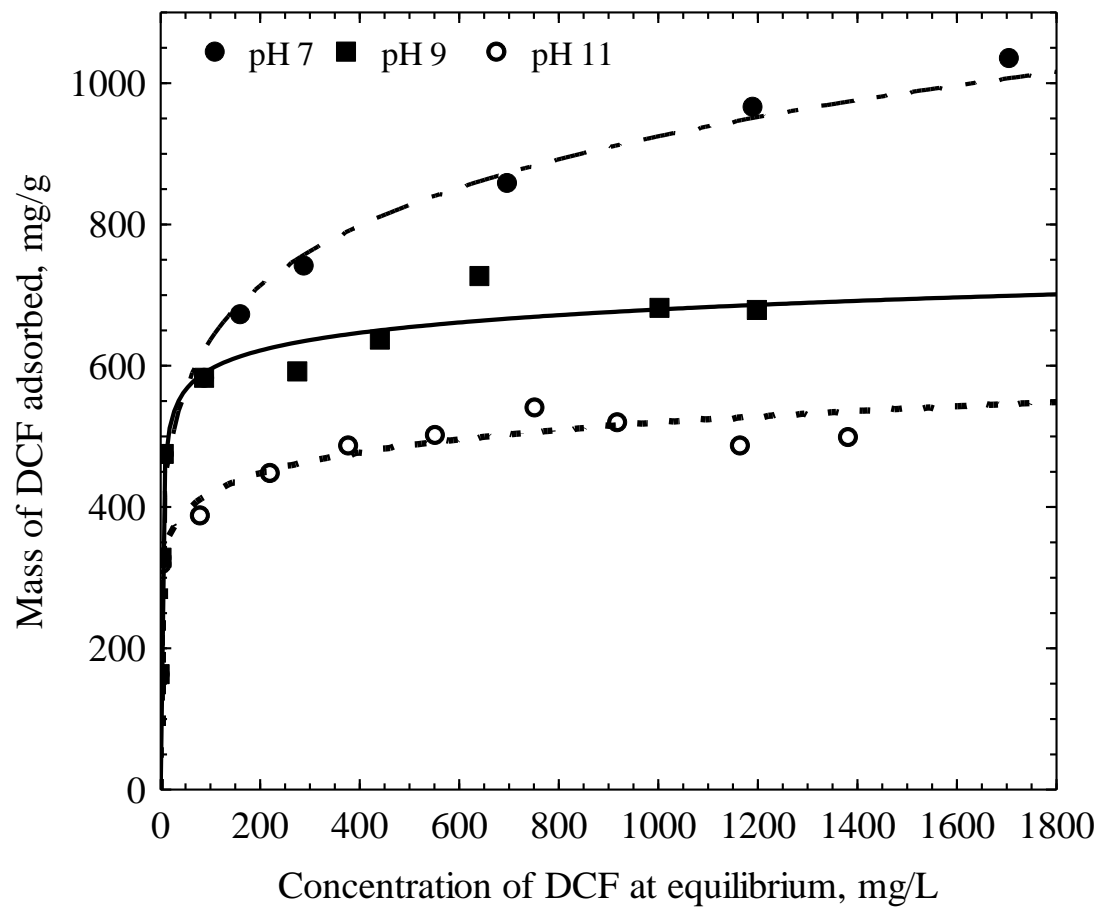

Fig. 5 


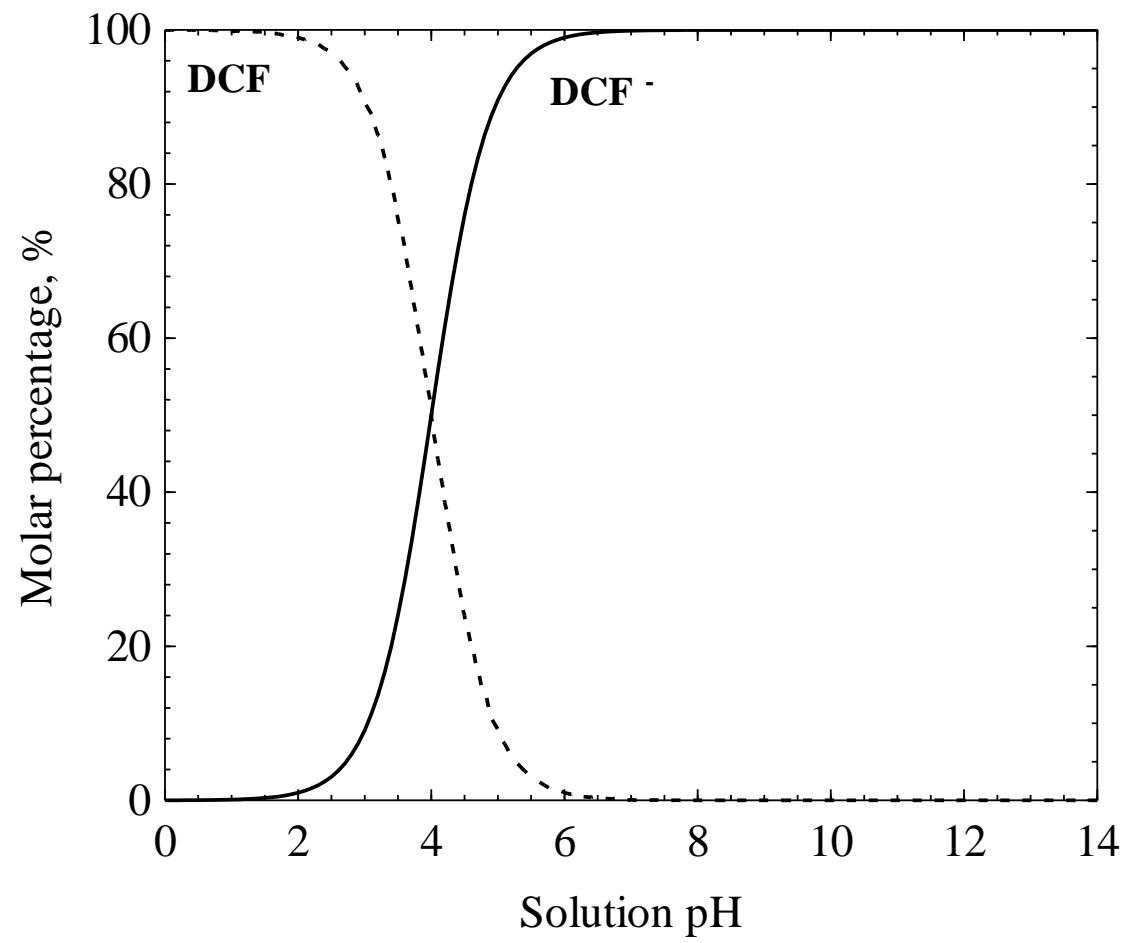

Fig. 6 


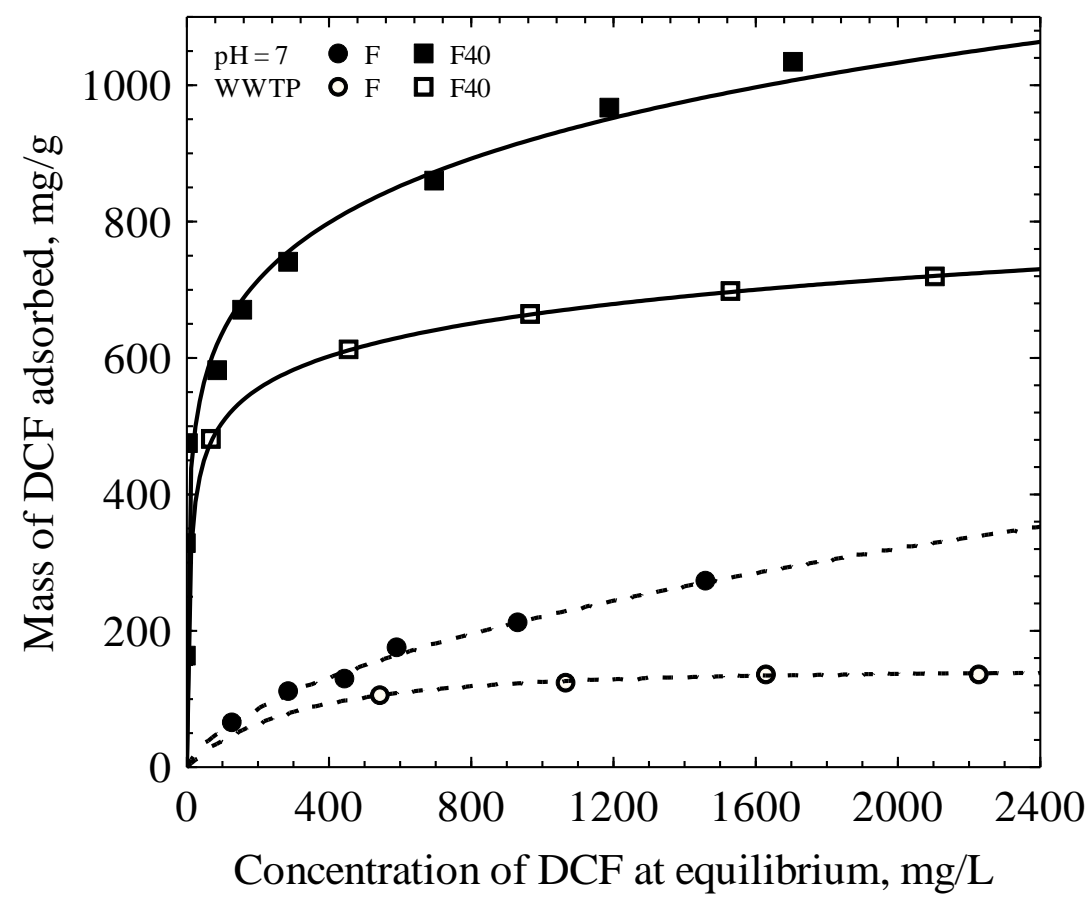

Fig. 7 